\title{
0 (re)florestamento e os incentivos para introdução da monocultura de Pinus spp no planalto de Santa Catarina, Brasil
}

The (re)forestation and incentives for the introduction of Pinus spp monoculture in the Santa Catarina plateau, Brazil

\author{
Samira Peruchi Moretto* \\ [samira.moretto@uffs.edu.br]
}

Recibido: 9 -de agosto de 2016

Aprobado: 23 de diciembre de 2016

DOI: $10.5935 / 2237-2717.20160017$

Citação sugerida: Moretto, Samira P. "0 (re)florestamento e os incentivos para introdução da monocultura de Pinus spp no planalto de Santa Catarina, Brasil." HALAC VI, no. 2 (Diciembre 2016): 298-310.

\begin{abstract}
RESUMO
0 Estado de Santa Catarina apresentou um histórico de intensa devastação ao longo do século XX. Mesmo durante o processo de desmatamento que ocorreu no Estado, entre as décadas de 1920 e 1970, já era previsto que o mesmo poderia se tornar algo imensurável e acarretaria perdas irrecuperáveis ao meio ambiente. Por este fato, 0 governo federal, juntamente com 0 governo estadual, criou decretos e outras legislações que asseguravam o reflorestamento no Estado, para manutenção da flora. No entanto, durante várias décadas, as principais preocupações por parte do governo do Estado de Santa Catarina, com relação à floresta, se limitavam a questões em prol da continuidade da ascensão econômica gerada pelo setor madeireiro. Neste momento crescia o reflorestamento com espécies exóticas como Pinus ssp e o Eucalyptus, que ameaçam 0 ecossistema. 0 plantio de espécies exóticas não era restrito e nem discriminado no Código Florestal de 1965, e os interessados no plantio podiam até receber incentivos fiscais para seu plantio. 0 objetivo deste artigo é analisar a legislação brasileira no que tange ao reflorestamento e os incentivos a introdução de espécies madeiráveis exóticas, no planalto catarinense durante 0 século XX.
\end{abstract}

\section{Palavras chaves}

História Ambiental, Pinus spp, Reflorestamento, Santa Catarina, Brasil.

\section{ABSTRACT}

The State of Santa Catarina presented a history of intense devastation throughout the 20th century. Even during the process of deforestation that occurred in the state between the 1920s and 1970s, it was already predicted that it could become immeasurable and would lead to irrecoverable losses to the environment. For this reason, the federal government, together with the state government, created decrees and other legislation that ensured the reforestation in the state, for the maintenance of the flora. However, for several decades, the main concerns of the state government of Santa Catarina, regarding the forest, were limited to issues in favor of the continuity of the economic rise generated by the timber sector. At this time, reforestation was growing with exotic species such as Pinus ssp and Eucalyptus, which threaten the ecosystem. The planting of exotic species was not restricted or discriminated against in the 1965 Forest Code, and those interested in planting could even receive tax incentives for planting. The objective of this article is to analyze the Brazilian legislation regarding reforestation and the incentives to introduce exotic timber species in the Santa Catarina plateau during the 20th century.

\section{KEYWORDS}

Environmental History, Pinus spp, Reforestation, Santa Catarina, Brazil.

\footnotetext{
* Doutora em História Ambiental. Professora do Dēpartamento de História da Universidade Federal da Fronteira Sul (UFFS), Chapecó, Brasil.
} 
No Brasil, há no mínimo cinco séculos, a natureza é vista como fonte de renda, e os recursos naturais que existiam em abundancia passaram a ser contabilizados. A natureza tornou-se sinônimo de mercadoria, deixando de lado qualquer avaliação prévia ou precauções com os riscos e conservação do meio ambiente ${ }^{1}$. Dentro desta perspectiva, o Estado de Santa Catarina apresentou um histórico de intensa devastação ao longo do século XX. A Floresta Ombrófila Mista, que ocupava 42,5\% da área do Estado, atualmente tem seus remanescentes foram avaliados em 0,07\%. Mesmo durante o processo de desmatamento que ocorreu no Estado, entre as décadas de 1920 e 1970, já era reconhecido que o desmatamento poderia se tornar algo imensurável e acarretaria perdas irrecuperáveis ao meio ambiente. O objetivo deste artigo é analisar a legislação brasileira no que tange ao reflorestamento e os incentivos a introdução de espécies madeiráveis exóticas, no planalto catarinense durante o século XX.

A devastação da Floresta Ombrófila Mista foi responsável pela movimentação econômica no planalto Catarinense. Foram no mínimo cinco décadas de derrubadas desenfreadas, seguidas do reflorestamento, ambas as atividades afirmando a importância e necessidade de serem estudadas. José Augusto Drummond sugere que o meio ambiente pode ser avaliado dentro da teoria econômica dos ciclos, onde o extrativismo vegetal é colocado como um dos ciclos de exploração econômica², assim como a cana-de-açúcar e o ouro um dia foram.

A história ambiental pode contribuir nos próximos anos para que se atinja um meio termo entre os "ciclos estanques" e os "ciclos abstratos". A melhor agenda para um possível grupo de historiadores ambientais talvez seja retomar o tema dos ciclos econômicos da história colonial e independente do Brasil, em clave ambiental. O objetivo seria identificar, em escala regional e local, que tipos de sociedade se formaram em torno de diferentes recursos naturais, que permanência tiveram essas sociedades e que tipo de conseqüências elas criaram para os seus ambientes sustentarem outros tipos de sociedade. ${ }^{3}$

Haviam indiscriminados incentivos ao desmatamento, mas pouco havia de preocupação com a conservação ou preservação da flora catárinense. As questões referentes ao reflorestamento e principalmente com conservação no âmbito nacional brotaram de forma tímida no início do século XX. Em 1911 foi criado o Instituto Florestal ${ }^{4}$ brasileiro, por Albert Löfgren, ${ }^{5}$ com o intuito de preservar as florestas do país. Com as falhas na legislação e na fiscalização, não foi possível assegurar proteção às matas. No entanto, a criação do Instituto foi acompanhada de discussões quanto à necessidade de preservar. Somente no dia 23 de janeiro de 1934 foi instituído o primeiro Código Florestal Brasileiro,

\footnotetext{
${ }^{1}$ Barcelos, Gilda Helena. A Crise ambiental e a Mercantilização da Natureza. In: Hissa, Eduardo Viana (org). Saberes ambientais: desafios para o conhecimento disciplinar (Belo Horizonte: Editora UFMG, 2008), 109.

${ }^{2}$ Este paradigma de ciclos econômicos no Brasil fôi contestado por João Fragoso e Manolo Florentino por acreditarem em uma economia dinâmica, onde várias atividades comerciais aconteceram simultaneamente, a partir da chegada dos portugueses. Florentino, Manolo; Fragoso, João. O Arcaísmo como Projeto. (Rio de Janeiro: Editora Civilização Brasileira, 2001)

${ }^{3}$ Drummond, José Augusto. A História ambiental: temas, fontes e linhas de pesquisa. Estudos Históricos, (Rio de Janeiro, vol. 4, n. 8, 1991), 177-197.

${ }^{4}$ Marcondes, Sandra. Brasil, amor à primeira vista! Viagem Ambiental no Brasildo século XVI ao século XXI. (São Paulo: Editora Peirópolis, 2005), 140.

${ }^{5}$ Albert Löfgren nasceu em 1834 em Estocolmo na Suécia e formou-se em Filosofia e Ciências Naturais. A convite de Andrés Frederick Ragnell veio para o Brasil e residiu por muitos anos em São Paulo, onde trabalhou como botânico e meteorologista, e onde esteve em contato com a destruição da floresta. Foi diretor do Instituto Florestal de São Paulo.
} 
pelo decreto $n^{\circ}$. 23.793, mesmo assim raramente aplicado e pouco efetivo diante das inúmeras irregularidades.

O Código Florestal de 1934 preocupava-se com a manutenção, preservação e uso racional dos recursos florestais brasileiros. Sendo a primeira legislação específica para a questão ambiental, mostrou-se pouco preocupada com as questões ligadas ao reflorestamento. Na Secção III, onde fora legalizada a Exploração Intensiva, primeiramente, é enfático na obrigação do reflorestamento de áreas desmatadas com a função de exploração econômica:

Art. 49. Na exploração de florestas de composição homogênea, o corte das árvores far-se-a de forma a não abrir clareiras na massa florestal. Parágrafo único. As árvores abatidas, salvo as que já se estiverem renovando por brotação, serão substituídas por mudas da mesma espécie ou por outra essência florestal julgada preferível, devidamente selecionada, sempre com o espaçamento que a técnica exige. ${ }^{6}$

Mesmo exigindo o replantio de áreas desmatadas, o governo federal não definiu de forma clara as espécies que poderiam ser utilizadas como forma de reflorestamento. Assim, uma série de espécies exóticas foi introduzida já na década de 1930, ameaçando a flora nativa que fora intensamente desmatada. Dentro da legislação havia uma ressalva aos proprietários de terrenos compostos pela floresta heterogênea, legalizando a sua transformação para uma floresta homogênea, ou seja, composta por apenas uma espécie:

Art. 51. É permitido aos proprietários de florestas heterogenias, que desejarem transformá-las em homogêneas, para maior facilidade de sua exploração industrial, executar trabalhos de derrubada, ao mesmo tempo, de toda a vegetação que não houver de subsistir, sem a restrição do art. 23, contanto que, durante o inicio dos trabalhos, assinem, perante a autoridade florestal, termo de obrigação de replantio e trato cultural por prazo determinado, com as garantias necessárias. ${ }^{7}$

Na sequência do Código Florestal de 1934 são levantadas as questões em torno das punições decorrentes do não cumprimento da legislação vigente. Dentre as penalidades as mais comuns eram: prisão, detenção e multas. Tais punições eram restritas a destruição da floresta, como atear fogo, invadir áreas protegidas, inserir pragas ou soltar animais em áreas impróprias. Não havendo assim, nenhuma punição discriminada a quem deixasse de reflorestar as áreas desmatadas.

Dentro do Código de 1934 ficou também instituída a criação de um Conselho Florestal Federal, com sede no Rio de Janeiro, constituído pelos representantes: do Museu Nacional, do Jardim Botânico, da Universidade do Rio de Janeiro, do Serviço do Fomento Agrícola, do Touring Club do Brasil, do Departamento Nacional de Estradas, do Serviço de Florestas, ou de Matas, da Municipalidade do Distrito Federal, e ainda por outras, de notória competência especializada, nomeadas pelo presidente da República. Esses representantes ficariam responsáveis por "promover e zelar pela fiel observância deste código e leis, ou

${ }^{6}$ Brasil. Decreto n. 23.793, de 23 de janeiro de 1934 (Rio de Janeiro, 1934).

7 lbid. 
regulamentos complementares, acompanhando a ação das autoridades florestais e representando-lhes sobre necessidades ou deficiências dos serviços, ou sobre reclamos do interesse público."

A execução e a fiscalização foram delegadas a uma série de órgãos estaduais e municipais. O andamento dos processos era algo lento e descontínuo por haver muitas instituições envolvidas. Warren Dean expôs as fragilidades do Código Florestal de 1934, questionando a validade e cumprimento das promessas feitas durante sua criação. Na tentativa de melhorar a fiscalização, foi transferido à polícia civil o cargo de exigência no cumprimento da legislação do Código de 1934. A falta de preparo para tal cargo fez também deste um projeto fracassado, por isso Dean afirma que "o principal defeito do código, de fato, era que ele nunca havia sido cumprido: nunca foram alocados fundos suficientes e, por muitos anos, sua aplicação era fiscalizada por voluntários, muitos dos quais em busca de propinas."

As primeiras iniciativas para o reflorestamento por parte do governo catarinense surgiram no final da década de 1930, quando o governador Nereu Ramos aprovou o Decreto-lei no 132, que visava a recuperação e conservação da floresta. O governador colocou-se disposto a preocupar-se com a manutenção da floresta com espécies nativas da região, afirmando: "Considerando que a extração de madeiras, para quaisquer fins industriais, deve ser feita de modo que, pelo plantio, seja assegurada a 'feição de floresta originária'." 10

As questões que ganham destaque no Decreto-lei catarinense estão intimamente ligadas ao setor econômico madeireiro e ao potencial que se revelava no Estado na primeira metade do século XX. No decorrer do termo legal o reflorestamento aparece seguido da inexistência de uma classificação ou exigência de com qual espécie o replantio deve ser feito. A "feição de floresta originária" vai ganhando significado diferente, isto é, não é interpretado como obrigatório o replantio com espécies nativas, como é apresentado nos artigos subseqüentes.

No Art. 6 do mesmo Decreto-lei é abordado quais espécies deveriam ser reflorestadas: "Art. 6 - As árvores abatidas serão substituídas por mudas da mesma espécie ou de outra essência florestal, julgada conveniente, devidamente selecionadas e com o espaçamento que a técnica exige." ${ }^{11}$ Esse julgamento se torna ambíguo e pouco substancial, dando margens a uma série de interpretações e levando ao reflorestamento uma grande variedade de espécies, ou seja, quando ele èra realizado, já que a fiscalização no estado de Santa Catarina era precária.

Em 1949 existiam 19 municípios com agentes florestais e em todo o Estado apenas 10 municípios que possuíam delegado. Destes 10, apenas em três o delegado e o agente não eram a mesma pessoa. ${ }^{12}$ Isto é, uma área de $95.346 \mathrm{~km}^{2}$, era fiscalizada por 19 agentes florestais, na metadade do século XX, depois de mais de dez anos de vigor do Cógigo Florestal.

A falta de preparo e fiscalização era notada pela população, que se mostrava preocupada com as reservas naturais. É de se destacar que mesmo havendo receio com a falta de cuidados por parte do governo em não executar a legislação, o que mais chamava.a

\footnotetext{
${ }^{8} \mathrm{lbid}$.

${ }^{9}$ Dean, Warren. A ferro e fogo: a história e devastação da Mata Atlântica brasileira. (São Paulo: Companhia das Letras, 1996), 303.

${ }^{10}$ Decreto de Lei 132. Relatório apresentado em outubro de 1938 ao exmo.sr. Presidente da República, pelo Dr. Nereu Ramos, Interventor Federal no Estado de Santa Catarina. Acervo: APESC.

${ }^{11}$ Ibid.

${ }^{12}$ Relatório de Diversos Órgãos -Agricultura-Relatório de Serviço Florestal. (Santa Catarina, 1949), Acervo: APESC.
} 
atenção até praticamente a década de 1970 era simplesmente a manutenção das indústrias madeireiras que se espalhavam principalmente pelo planalto catarinense. Havia, sim, zelo pela economia local lageana, que empregava e mantinha o bem estar social. No entanto, não havia uma preocupação ideológica forte para a preservação da floresta e o replantio voltado pra preservação.

O Jornal Correio Lageano, de 1944, comenta o Código Florestal de 1934 e chama a atenção para o desmatamento imensurável que acontecia não apenas na região de Lages, como em todo o país:

\begin{abstract}
A terra nua, varrida pelos ventos e roída pelas enxurradas, hoje cobra o duro preço do seu empobrecimento pela loucura dos que trataram a mata a ferro e fogo. Contra o crime clamou Alberto Torres ${ }^{13}$. Seu protesto era a advertência que dirigia aos responsáveis pela gestão da coisa pública para que se adotassem imediatas medidas de proteção destinadas a resguardar o que ainda restava do nosso patrimônio florestal. Clamou em nome do futuro. Clamou pelo amor da Pátria. Em vão falou o pensador. O machado empunhado mais por anos aventureiros que dirigido pelo bom senso, prosseguiu a obra demolidora. Graças felizmente a uma melhor compreensão, nos últimos tempos, Torres começou a ser ouvido. Providências oficiais foram adotadas contra as derrubadas inúteis. Surgiu o Código Florestal. Sobre essa importante peça básica assenta toda a legislação regional sobre o assunto. Desde então, aos Estados incumbe organizar, em seus respectivos territórios, a proteção às florestas remanescentes, assim como fomentar o florestamento e o reflorestamento das terras disponíveis. ${ }^{14}$
\end{abstract}

A matéria finda afirmando a importância não apenas da existência de um Código Florestal, mas também, a necessidade dele ser forte a atuante, para não resultar na escassez das florestas. Essa cobrança era condizente com a situação do Estado: mesmo estando em vigor o Código Florestal, os órgãos estaduais haviam registrado, no ano de 1948, 703 serrarias no Estado. ${ }^{15}$ Destas, 157 estavam localizadas no município de Lages.

Na década de 1940, mais um importante órgão com função de preservação e manutenção da floresta é criado. Pelo Decreto-lei no 3.124, de março de 1940, Getúlio Vargas cria o Instituto Nacional do Pinho (I.N.P.), onde é delegada aos Estados do Rio Grande do Sul, Paraná e Santa Catarina a função de coordenar o órgão oficial dos interesses dos produtores, industriais e exportadores de pinho, com sede na Capital da República, administrativa e financeiramente autônomo. ${ }^{16}$ Dentro deste decreto, o Capítulo VII é referente ao reflorestamento:

Art. 15. O Instituto contribuirá para o reflorestamento, com o replantio das espécies determinadas pelos técnicos do Ministério da Agricultura. Em terras adquiridas para esse fim, ou coadjuvando iniciativa particular, na forma que for estabelecida pelo regulamento. Art. 16. Os Governos estaduais auxiliarão a

\footnotetext{
${ }^{13}$ Alberto Torres foi um dos pensadores ruralistas brasileiros. Publicou em 1914 os livros O problema nacional brasileiro e $A$ organização nacional e, em 1915, As fontes da vida no Brasil, nos quais concebia o Brasil como um país de natureza essencialmente agrária, opondo-se assim a qualquer veleidade industrialista. Nacionalista, defendia o fortalecimento do Executivo, convocando os intelectuais a participar da organização da sociedade. Dentre suas obras tecia comentário sobre a necessidade de conservação da floresta e dos recursos naturais.

${ }^{14} \mathrm{O}$ reflorestamento. Correio Lageano. (Lages 04 de março de 1944), 03.

${ }^{15}$ Relatório do Serviço Florestal do Estado de Santa Catarina. (Santa Catarina, 1948).

${ }^{16}$ Brasil. Decreto-lei No. 3.124, de 19 de março de 1941. (Rio de Janeiro, 1941).
} 
multiplicação de parques e poderão assumir os ônus de sua administração, mediante acordo com o Instituto. Parágrafo único. A contribuição do Instituto para o reflorestamento será proporcional à renda arrecadada em cada Estado. ${ }^{17}$

A preservação da floresta contrariava as intenções de exploração de muitos empresários do setor madeireiro. Era intensa a movimentação econômica na região em função da extração da madeira. A floresta nativa com rico volume madeirável era visada e derrubada, e a fiscalização se mostrava impotente perante tal situação.

Em 16 de fevereiro de 1948 foi firmado um acordo entre o Governo do Estado e a União, criando o "Acordo Florestal", que tinha como finalidade a execução de serviços relativos ao florestamento, reflorestamento e proteção das matas do Estado. A coordenação do Acordo Florestal era diretamente subordinada ao Ministério da Agricultura e a prestação de contas era realizada através de um relatório redigido anualmente.

O fato de não haver uma fiscalização eficiente era agravado pela existência de um número realmente reduzido de funcionários para a fiscalização e exigência do cumprimento da lei. O número de funcionários era relativamente o mesmo apresentado em 1948, já aqui citado. Em 1951, havia 21 agentes florestais, 13 guardas e 5 Delegados Florestais simples. ${ }^{18}$ Por todos esses motivos, os funcionários alegavam que o serviço de proteção florestal não poderia apresentar a eficiência desejada, uma vez que sua organização baseia-se na nomeação de pessoas sem remuneração e sem o necessário preparo para o exercício do cargo.

Presente no mesmo Relatório havia queixas dos representantes do conselho sobre a dificuldade na manutenção da legislação referente à proteção das florestas existentes no Estado. Era colocado que: "As derrubadas e os incêndios florestais continuam a se registrar anualmente, em proporções cada vez maiores, sem que se tenham os meios necessários para coibir tais abusos, obrigando que toda exploração de mata seja feita de conformidade com o disposto nas citadas leis."

O desmatamento continuava, em grande escala e sem controle florestal adequado. Os registros de serrarias cresciam e no ano de 1951 foram emitidos no Estado 2.080 certificados de regulamentação e funcionamento de serrarias, sendo 1.800 renovações dos registros já existentes e 280 novas serrarias criadas a partir de $1938 .{ }^{20}$

Na década de 1950 os madeireiros alegavam descaso por parte do governo e falta de incentivos para o manejo e a exploração da madeira. Os madeireiros enfrentavam problemas com a redução de árvores e com a falta de financiamento do governo:

Corroborando discurso do deputado Fernando Ferreira de Melo, seu companheiro de bancada, o ilustre representante de Porto União, aconselha com fundamentados argumentos, a transformação do atual Instituto do Pinho num banco de produção com a finalidade precípua de atender as necessidades dos madeireiros e aliviar-lhes as crises nos momentos oportunos. As dificuldades que enfrenta, atualmente a classe madeireira do Estado, residem na falta de financiamento e de estoques. ${ }^{21}$

\footnotetext{
${ }^{17} \mathrm{Ibid}$.

${ }^{18}$ Ibid.

${ }^{19}$ Relatório do Acordo Florestal com o Estado de Santa Catarina. (Santa Catarina,1951), 09

${ }^{20}$ Ibid.

${ }^{21}$ A Crise da Madeira. Região Serrana. (Lages ,15 de junho de 1950), 03.
} 
As pressões apenas se alargavam, pois o governo ao mesmo tempo tinha interesse em manter os quadros favoráveis de exportação de madeira, mas sem deixar que a mesma se esgotasse por falta de uma legislação que incentivasse o reflorestamento com araucárias e outras árvores nativas da região. A década de 1950 foi considerada o fim do ciclo da extração dos grandes pinheiros, precedendo a crise que se instalou na década de 1960

Em função dos graves problemas ambientais acompanhados da falta de fiscalização e de uma legislação consistente, no início da década de 1960 o Código Florestal de 1934 foi reavaliado e constatou-se a necessidade da criação de uma nova legislação voltada ao meio ambiente.

Assim, pela Lei n. 4.771, de 15 de setembro de 1985, é instituído o novo Código Florestal, que se propunha a cobrir as brechas do Código anterior. Uma boa parte da legislação refere-se ao controle do corte indiscriminado das áreas florestais do país. As primeiras prerrogativas são referentes às florestas existentes no território nacional e às demais formas de vegetação, que passavam a ser reconhecidas como de utilidade às terras que revestem; são bens de interesse comum a todos os habitantes do país, exercendo-se os direitos de propriedade, com as limitações que a legislação em geral e especialmente esta Lei estabelecem. ${ }^{22}$

No Código de 1965 três artigos referem-se ao reflorestamento propriamente dito. O primeiro deles, o Artigo 18, se refere ao reflorestamento de áreas particulares: "Nas terras de propriedade privada, onde seja necessário o florestamento ou o reflorestamento de preservação permanente, o Poder Público Federal poderá fazệ-lo sem desapropriá-las, se não o fizer o proprietário". ${ }^{23}$

Iniciou-se, assim, o processo de conservação, ao menos legalizado, e manejo das áreas de preservação permanente, em terrenos que pertenciam a proprietários distintos da União. Dentro da legislação não fora estipulado de que forma seria feito o reflorestamento e nem estabelecida a penalidade a ser aplicada com a falta de cumprimento de tal exigência.

O outro artigo referente ao reflorestamento era específico sobre o financiamento que o governo proveria para os proprietários interessados no plantio de árvores. O governo responsabilizava-se pela disposição dos créditos e das máquinas, e também dava prioridade em distribuir os financiamentos aprovados pelo Conselho Florestal Federal, como pode ser observado a seguir no Art. 41:

Os estabelecimentos oficiais de crédito concederão prioridades aos projetos de florestamento, reflorestamento ou aquisição de equipamentos mecânicos necessários aos serviços, obedecidos as escalas anteriormente fixadas em lei. Parágrafo único. Ao Conselho Monetário Nacional, dentro de suas atribuições legais, como órgão disciplinador do crédito e das operações creditícias em todas suas modalidades e formas, cabe estabëlecer as normas para os financiamentos florestais, com juros e prazos compatíveis, relacionados com os planos de florestamento e reflorestamento aprovados pelo Conselho -Florestal Federal. ${ }^{24}$

${ }^{22}$ Código Florestal de 1965. Lei № 4.771, (Brasil 15 de setembro de 1965).

${ }^{23} \mathrm{Ibid}$.

${ }^{24}$ Ibid. 
O Artigo 41 do Código Florestal de 1965 abordou de forma mais profunda o reflorestamento. No entanto, tal artigo deixa de lado prerrogativas fundamentais como a descrição da forma que o reflorestamento deveria ser aplicado e quais as espécies que deveriam ser utilizadas para o mesmo.

A falta de descrição de com quais espécies deveria ser feito o reflorestamento no Código Florestal de 1965 deu abertura para uma série de irregularidades no processo de liberação de créditos para inserção de distintas espécies. Como não foi estipulado que o replantio deveria ser feito com espécies nativas ou simplesmente delimitado as espécies que não poderiam ser consideradas próprias para o replantio, o reflorestamento passou a ser feito com espécies exóticas e também com árvores frutíferas. As espécies exóticas como o Pinus spp e o Eucalyptus foram preferíveis não pelo seu valor comercial, mas sim por sua maturidade precoce comparada a espécies nativas.

Apoiados na legislação de 1965, produtores agrícolas viram a oportunidade de conseguirem financiamentos por parte do governo, pois poderiam utilizar árvores frutíferas para o reflorestamento e receberiam para isso um apoio financeiro governamental, e assim obteriam uma nova fonte de renda. Foi neste momento que muitas cidades do planalto catarinense conseguiram o financiamento para a implantação da fruticultura, como afirmam Klanovicz e Nodari, na análise sobre a implementação da macieira no município de Fraiburgo:

Para implantar seus pomares e viveiros, era necessário investir tempo e dinheiro na preparação inicial do terreno de plantio e a SAFRA (Sociedade Agrícola Fraiburgo) trabalhava incessantemente na transformação da paisagem para esse fim. Os desmatamentos das futuras áreas de plantio beneficiavam não somente a empresa, mas também outros setores da economia, em especial a manutenção das atividades da serraria dos irmãos Frey, também sócios da SAFRA. Na prática, a idéia da implementação de "arvoredos homogêneos" era muito relativa. Para o engenheiro agrônomo Jorge Bleicher, a paisagem em Fraiburgo poderia ser transformada em projetos de reflorestamento. ${ }^{25}$

O cultivo de plantas frutíferas para a comercialização desde a década de 1920 era estimado como fonte de renda. Para a cidade de Fraiburgo, a implementação de tal cultura movimentou as exportações madeireiras, em função do desmatamento, e as exportações de frutas, no caso específico da maçã. O jornal $A$ Época de Lages, já nas primeiras décadas do século XX, fazia a promoção e o incentivo para a produção frutífera no Estado, chamando a atenção para a falta de continuidade nos cuidados com as plantas:

Sob o título "Uma nova fonte de riquezas" publicamos hoje um artigo que nos faz prever um futuro promissor de melhores prosperidades para esta região. Diante das demonstrações claras ali encontradas, ninguém poderá deixar de crer que muito breve nossas frutas serão reduzidas a dinheiro. O plantio de árvores frutíferas entre nós, há mais de vinte anos que foi começado. Como, porém, por circunstancias diversas, as frutas não tivessem saída, não se cuidou em multiplicar a plantação, ficando em completo abandono o arvoredo existente. ${ }^{26}$

\footnotetext{
25 Klanovicz, Jó; Nodari, Eunice. Das Araucárias às Macieiras: transformações da paisagem em Fraiburgo/SC. (Florianópolis: Insular, 2005), 65-66.

${ }^{26}$ A Fruticultura como fonte de renda. A Época. (Lages, 18 de novembro de 1928) 05
} 
Além da opção de fazer o reflorestamento com árvores frutíferas, neste momento crescia o reflorestamento com espécies exóticas madeiráveis, como é o caso do Pinus spp e do Eucalyptus. O plantio de espécies exóticas não era restrito e nem discriminado no Código. Florestal de 1965, e os interessados no plantio recebiam até incentivos fiscais para seu plantio.

O Código de 1965 foi responsável ainda pela criação da Semana Florestal, onde havia uma prerrogativa sobre reflorestar:

Art. 43. Fica instituída a Semana Florestal, em datas fixadas para as diversas regiões do País, do Decreto Federal. Será a mesma comemorada, obrigatoriamente, nas escolas e estabelecimentos públicos ou subvencionados, através de programas objetivos em que se ressalte o valor das florestas, face aos seus produtos e utilidades, bem como sobre a forma correta de conduzi-las e perpetuá-las. Parágrafo único. Para a Semana Florestal serão programadas reuniões, conferências, jornadas de reflorestamento e outras solenidades e festividades com o objetivo de identificar as florestas como recurso natural renovável, de elevado valor social e econômico. ${ }^{27}$

O Código Florestal de 1965, como o Código de 1934, foi visto igualmente como falho e com brechas que colocavam a biodiversidade brasileira em risco. Warren Dean afirma que o próprio código era suficiente para eliminar toda árvore nativa ainda existente:

Embora o proprietário fosse obrigado a manter $20 \%$ da sua terra florestada, não havia, tal como antes, nenhum dispositivo contra a venda dessa faixa de mata a um comprador, que podia cortar até $80 \%$ da mesma. O governo também não repudiava a destruição de "florestas de preservação permanente", embora os casos de "utilidade publica ou interesse social" ficassem sujeitos a aprovação do presidente. [...] Incentivos fiscais eram insuficientes para convencer os proprietários particulares a preservar a floresta primaria ou plantar florestas permanentes. ${ }^{28}$

O fim da década de 1960 foi marcado por um impasse extremamente prejudicial ao meio ambiente. No período da ditadura militar os preceitos de desenvolvimento não se restringiam frente à idéia da conservação dos biomas. Assim, o desenvolvimento econômico, tão almejado pelos militares, fora colocado à frente da conservação dos recursos naturais. O Código Florestal de 1965 só veio reforçar a idéia de que o meio ambiente era secundário e precisava ser sacrificado em prol do "desenvolvimento" - o utilitarismo do meio prevalecia à preservação do mesmo. Na década de 1960 também foi extinto o Instituto Nacional do Pinho, em detrimento da criação do Instituto Brasileiro de Desenvolvimento Florestal (IBDF).

O presidente Emílio G. Médici aprovou o regulamento da Lei número 5.106, de 2 de setembro de 1966 e do Decreto-lei n. 1.134, de 16 de novembro de 1970, que dispõe sobre os incentivos fiscais para o desenvolvimento florestal no país. Este documento procura especificar os casos de apoio financeiro disponibilizado pela União para o florestamento e reflorestamento no país, e coloca as seguintes condições em um parágrafo único:

\footnotetext{
${ }^{27}$ Brasil. Código Florestal de 1965. (Brasília, 1965), Artigo 43.

${ }^{28}$ DEAN, Warren. A ferro e fogo, 304 e 305.
} 
Dos Empreendimentos Florestais: Art. $1^{\circ}$ Os empreendimentos florestais que possam servir de base à exploração econômica, à conservação do solo e dos regimes das águas, e que contribuam para o desenvolvimento florestal do País, através do florestamento ou reflorestamento, poderão ser objeto dos incentivos fiscais de que trata este Regulamento. $\S 1^{\circ}$ Os empreendimentos florestais a que se refere este artigo serão objeto de projetos específicos, anuais ou plurianuais, elaborados de acordo com o presente Regulamento. $\S$ $2^{\circ}$ Os projetos de empreendimentos florestais deverão ser submetidos, previamente, ao Instituto Brasileiro de Desenvolvimento FLORESTAL - IBDF, a fim de poderem ser considerados como aptos a receber incentivos fiscais. Art. $2^{\circ}$ Os empreendimentos florestais poderão ser realizados por pessoas físicas ou jurídicas, residentes ou domiciliadas no País. ${ }^{29}$

Juntamente com este decreto o governo colocou-se disposto a financiar a silvicultura no país, sem muitas especificações com relação às espécies que deveriam ser utilizadas. Nas Disposições Gerais deste mesmo decreto existe a imposição de que: "Nenhum projeto poderá ser aprovado se não previr um programa de plantio mínimo de 1\% (um por cento) de essências típicas da região especialmente valiosas." "Este artigo não especificou quais espécies compõe as "espécies valiosas", podendo ter uma conotação que agrega valores monetários ou no sentido de que são espécies raras que precisam ser conservadas. A porcentagem a ser reflorestada com espécie nativa foi estipulada em 1\%, mas poderia mudar de acordo com a aprovação do IBDF (Instituto Brasileiro de Desenvolvimento Florestal), como constava no parágrafo único do Art. 23: "Fica a critério do IBDF aumentar a percentagem estabelecida neste artigo." ${ }^{11}$

A Lei Federal no. 5.106 entrou em vigor em 1966, conhecida como Lei de Incentivos Fiscais para replantio, que permitia que até $50 \%$ do imposto de renda fosse empregado em atividades de florestamento e reflorestamento. Para poder aplicar tal valor era necessário apresentar um projeto para ser avaliado e aprovado pelo hoje extinto Instituto Brasileiro de Desenvolvimento Florestal, o IBDF, compreendendo um plantio mínimo de 10.000 árvores. ${ }^{32}$

Em 1967 o Código Florestal é promulgado. Algumas obrigações foram retificadas e entre elas, aparece a obrigação das indústrias que produziam carvão e extraiam madeira de plantar amplas florestas para suprirem suas necessidades. Surgiram também algumas contradições, como a extinção da cobrança de tributos a essas áreas plantadas e o abandono do princípio de que os proprietários deveriam proteger os mananciais, passando essa tarefa ao Estado. O IBDF foi criado com a função de ser uma "entidade autárquica, integrante da administração descentralizada do Ministério da Agricultura dotado de personalidade jurídica própria com sede e foro no Distrito Federal e jurisdição em todo o Território Nacional." 33

Uma das funções do IBDF era responsabilizar-se pelo projeto de florestamento e reflorestamento do país. O órgão fazia análise e opinava sobre os projetos de florestamento e reflorestamento elaborados para fins de usufruir os incentivos fiscais previstos em leis e regulamentos apropriados. Muitos projetos foram desenvolvidos e financiados pelo governo sem uma avaliação prévia do desgaste ecológico que resultariam.

\footnotetext{
${ }^{29}$ Brasil. Decreto lei n. ${ }^{\circ}$ 68.565, (Brasília, 29 de abril de 1971).

${ }^{30}$ Decreto lei n. ${ }^{\circ}$ 68.565, (Brasília, 29 de abril de 1971), Artigo 23.

${ }^{31} \mathrm{lbid}$.

${ }^{32}$ Frey, Willy. Reflorestar é a solução. (Paraná: Editora e gráfica Curitiba, 2003), 44-45.

${ }^{33}$ Brasil. Decreto-lei No 289, (Brasília, 28 de fevereiro de 1967).
} 
O IBDF elaborou planos indicativos, anuais e plurianuais de florestamento e reflorestamento nacionais e regionais, objetivando: I - a melhor alocação de recursos no setor; II - o desenvolvimento de espécies florestais de utilização econômica; III - o florestamento e reflorestamento com fins econômicos; IV - o florestamento e reflorestamento com fins ecológicos, turísticos e paisagísticos. ${ }^{34}$

O reflorestamento apoiado pelo Instituto visava claramente fins econômicos, por não se preocupar com a exigência de espécies, fossem elas exóticas ou nativas. As primeiras pressões para o reflorestamento vieram com penalidade para desobediência das determinações do IBDF sobre o reflorestamento de áreas devastadas; "foi prevista multa de até um por cento (1\%) do valor do salário-mínimo mensal da região por árvore não plantada, dobrando em cada reincidência." 35

No final da década de 1960 houve estímulos a partir das políticas monetárias, creditícias e fiscais. A concessão de isenções fiscais para o setor agrícola e para o setor florestal fazia parte do Plano de Governo e tinha como objetivo estimular as exportações dos produtos primários. ${ }^{36}$

Na década de 1970, pelo Decreto-lei n 52.370, foi criado o Instituto Florestal, que tinha como objetivo a proteção, a recuperação, a pesquisa e o manejo da biodiversidade e do patrimônio natural. Mantinha a mesma prerrogativa do Código Florestal de 1965, ao tratar do reflorestamento, já que se propunha "intervir no setor florestal, detendo o domínio das florestas de preservação permanente, e efetuar reflorestamento, como empresário florestal, com fins conservacionistas, técnicos e econômicos, de acordo com plano previamente aprovado."37

Com a vigência do Código Florestal, aumentavam o número de investimentos nos setores ligados ao reflorestamento para fins comerciais. O Estado de Santa Catarina promoveu um estudo denominado "Distrito Florestal", onde foi feito um levantamento sobre as possibilidades de aumentar o reflorestamento voltado ao mercado de consumo. A Secretaria da Agricultura e Abastecimento do Estado de Santa Catarina, com a parceria da Consultoria e Planejamento Florestal LTDA, elaborou o relatório com as seguintes metas: 1) Assegurar a produção econômica da madeira, em quantidade e qualidade necessária ao suprimento de matéria prima para a indústria existente; 2) Criar reserva de matéria prima para o suprimento das indústrias florestais que futuramente venham a se instalar; 3) Preservar as áreas de proteção permanente. ${ }^{38}$

O Projeto recebia respaldo do Governo Federal, pois executaria o Plano Nacional de Papel Celulose, que tinha como meta garantir através da criação de Distritos Florestais o suprimento de matéria prima florestal em condições econômicas e competitivas para atingir a auto-suficiência em produção de papel no País. Esses projetos patrocinados pelo governo militar não eram avaliados de forma ponderada e prejudicavam intensamente o meio ambiente e paradoxalmente imergiam o país em uma séria crise econômica. Dean afirma que: "Durante a década de 1970, a escala e a velocidade dos projetos de desenvolvimento do governo militar atingiram um clímax que não resultou apenas na crise econômica, mas

\footnotetext{
${ }^{34}$ Ibid.

${ }^{35}$ Brasil. Decreto-lei No 289, (Brasília, 28 de fevereiro de 1967), artigo 17

${ }^{36}$ ABREU, Marcelo Paiva de. (org). A ordem do Progresso: Cem anos de política econômica republicana (1889 - 1989). (Campinas: Editora Campus, 1995), 237.

${ }^{37}$ Brasil. Decreto-lei no. 52.370 - Criação do Instituto Florestal. (Brasília, 26 de janeiro de 1970).

38 Estudo Elaborado pela Secretaria da Agricultura e Abastecimento do Estado de Santa Catarina com a parceria da Consultoria e planejamento Elorestal LTDA, (Santa Catarina,1975), 09
} 
também em umà tempestade conjunta de desastres ambientais, desacreditando sua propalada preocupação com a segurança nacional."39

Os grandes desastres ambientais que ocorreram no século XX levaram aos questionamentos e posicionamentos da década de 1980. Há uma mudança na maneira de se relacionar com o meio ambiente, como afirma Donald Worster:

A idéia de uma história ambiental começou a surgir na década de 1970, à medida que sucediam conferências sobre a crise global e cresciam os movimentos ambientalistas entre os cidadãos de vários países. Em outras palavras, ela nasceu numa época de reavaliação e reforma cultural, em escala mundial. ${ }^{40}$

As discussões sobre a conservação do meio ambiente no perímetro acadêmico chegaram à escala pública e chamavam a atenção da população que passou a pressionar o governo. Assim como a questão ambiental aflora nas diferentes áreas de conhecimento, surge dentro da Ciência Jurídica a vertente do Direito Ambiental. Inspirada pela Carta de Estocolmo, a Constituição de 1988 declara em seu artigo 225 o direito ao meio ambiente sadio e ecologicamente correto. Legitimando, desta forma, dentro da Constituição, a necessidade de preocupar-se com o meio ambiente. Tanto as definições constitucionais como infraconstitucionais ressaltam a necessidade do meio ambiente ser visto a partir de uma concepção holística, que integre o homem ao mundo natural, descartando as visões meramente antropocêntricas. ${ }^{41}$

Surgiram debates no âmbito governamental para assegurar a manutenção dos recursos florestais do país. Dentro do mesmo artigo 225, foi definido que: "A Floresta Amazônica brasileira, a Mata Atlântica, a Serra do Mar, o Pantanal Mato-Grossense e a Zona Costeira são patrimônios nacionais e sua utilização far-se-á, na forma da lei, dentro de condições que assegurem a preservação do meio ambiente, inclusive quanto ao uso dos recursos naturais." ${ }^{2}$

Foi no final da década de 1980 que o governo federal preencheu uma lacuna do Código Florestal em relação ao reflorestamento, onde priorizou o uso de espécies nativas e delimitou uma porcentagem para o reflorestamento com espécies exóticas. Assim definiu:

III - o art. 19 passa a vigorar acrescido de um parágrafo único, com a seguinte redação: "Art. 19. A exploração de florestas e de formações sucessoras, tanto de domínio público como de domínio privado, dependerá de aprovação prévia do Instituto Brasileiro do Meio Ambiente e dos Recursos Naturais Renováveis IBAMA, bem como da adoção de técnicas de condução, exploração, reposição florestal e manejo compatíveis com os variados ecossistemas que a cobertura arbórea forme. Parágrafo único. No caso de reposição florestal, deverão ser priorizados projetos que contemplem a utilização de espécies nativas." ${ }^{43}$ (meus grifos)

\footnotetext{
${ }^{39}$ Dean, A ferro e fogo, 307.

40 Worster, Donald. "Para fazer História Ambiental" Estudos Históricos 4(8): 189-215, 1991, 199

${ }^{41}$ Marchesan, Ana Maria Moreira; Steigleder, Annelise Monteiro; Campelli, Sílvia. Direito Ambiental. (Porto Alegre: Verbo Jurídico, 2007), 27.

${ }^{42}$ Brasil. Constituição da Republica Federativa do Brasil. (Brasília, 1988), Artigo 225 - Parágrafo IV.

${ }^{43}$ Brasil. Lei n. ${ }^{0}$ 7.803, Altera a redação da Lei $n^{\circ} 4.771$, de 15 de setembro de 1965, e revoga as Leis $n^{\circ}$. 6.535, de 15 de junho de 1978, e n. ${ }^{\circ} 7.511$, de 7 de julho de 1986. (Brasília, 18 de julho de 1989).
} 
Mesmo com as necessárias alterações feitas na legislação; muitos empresários do ramo madeireiro continuaram a buscar novas brechas para burlar as exigências governamentais. Estudos realizados na década de 1990 afirmam que o Pinus elliottii tem suas sementes dispersas pelo vento, anemocóricas, dificultando o controle da espécie, podendo propagar suas sementes por centenas e até milhares de metros ${ }^{44}$, o que coloca os remanescentes da floresta em risco. A facilidade da expansão natural, a ausência de predadores naturais aliada ao plantio humano, faz com que o pinus spp seja uma grande ameaça à flora nativa. Nos anos seguintes, surgiram também estudos para a criação de Unidades de Conservação, não agradando o setor madeireiro, que passou a exercer pressão sobre os governantes para a diminuição das áreas protegidas.

\footnotetext{
${ }^{44}$ Richardson, David M. Ecology and Biogeography of Pinus. (USA: Cambridge University Press, 1998), 260.
} 